\title{
A TRANSPARÊNCIA DOS GASTOS PÚBLICOS EM SAÚDE NO MUNICÍPIO DE SÃO LUÍS/MA APÓS A LEI DE ACESSO À INFORMAÇÃO
}

\author{
TRANSPARENCY OF PUBLIC SPENDING ON HEALTH IN THE CITY OF SÃO \\ LUIS / MA AFTER THE INFORMATION ACCESS LAW
}

\section{RESUMO}

O Estado tem como uma de suas funções arrecadar recursos para devolvê-los à sociedade através da prestação de serviços. O objetivo do presente artigo é analisar a transparência das ações da gestão pública em saúde no município de São Luís (Maranhão) por meio da análise dos seus portais eletrônicos, após a Lei Federal no 12.527/2011 - Lei de Acesso à Informação Pública. Com base nos resultados da pesquisa, observou-se falhas quanto à divulgação clara das informações e ao cumprimento das exigências legais de acesso à informação pública, de modo a comprometer a transparência e a fiscalização dos gastos públicos.

Palavras-chave: Fiscalização dos gastos públicos. Lei de acesso à informação pública. Transparência. Serviços de saúde. Recursos públicos.

\begin{abstract}
The state has as one of its functions to raise funds to return them to society through the provision of services. The aim of this paper is to analyze the transparency of the actions of public health management in Sao Luis (Maranhão) through the analysis of their homepages, after the Federal Law nº 12,527 / 2011 - Public Information Access Law. Based on the search results, there was failure on the clear disclosure of information and compliance with the legal requirements for access to public information, in order to compromise transparency and public spending oversight.
\end{abstract}

Keywords: Public spending oversight. Public Information Access Law. Transparency. Health services. Public resources.

\footnotetext{
${ }^{1}$ Doutora em Políticas Públicas. Professora da Graduação e do Mestrado em Direito pela Faculdade Federal do Maranhão - UFMA, Maranhão, (Brasil). E-mail: edithramosadv@ yahoo.com.br

${ }^{2}$ Mestranda em Política e Instituições do Sistema de Justiça pelo Mestrado em Direito pela Universidade Federal do Maranhão - UFMA. Maranhão, (Brasil). E-mail: fernandadayane.queiroz@gmail.com
} 


\section{INTRODUÇÃO}

As discussões sobre a transparência dos gastos públicos e sua importância para os cidadãos tornaram-se mais relevantes. Como preleciona Campos et al. (2013) cada vez mais a população tem cobrado uma postura ética e transparente dos negócios públicos. Assim, quando o cidadão possui acesso à informação de receitas e gastos públicos, a possibilidade de haver cobranças referentes à repartição e utilização dos recursos públicos, tendo em vista as necessidades e anseios sociais, aumenta.

Este artigo busca fazer um estudo da divulgação em meio eletrônico de informações acerca da gestão pública em saúde no município de São Luís/MA. Pinho (2006) assevera que o município é o ente federativo mais próximo dos cidadãos e ao qual esses recorrem para suprir as principais demandas sociais. Desta forma, faz-se necessário, para o controle e conhecimento dos recursos disponíveis e gastos em âmbito municipal, o fornecimento das informações sobre a gestão dos recursos públicos sob responsabilidade dos gestores.

No mesmo sentido, Martins et al. (2013) consideram que promover a transparência é dar condição de acesso a todas as informações sobre a gestão pública. Uma Administração Pública transparente é aquela que funciona baseada em princípios éticos e democráticos, em função da facilidade que têm os cidadãos em acessar as informações públicas, tais como: documentos, atos oficiais, execução orçamentária, contratos celebrados pelo setor público em suas várias esferas.

Os portais de transparência pública visam aproximar o cidadão do Estado, a partir do acesso às informações financeiras sobre gestão do poder executivo, com o objetivo de evitar o uso inadequado do dinheiro público e viabilizar a consolidação da democracia. Segundo Pires et al. (2013), o tema transparência pública nunca esteve tão em evidência. Isso se deve, ainda para os autores, em virtude da busca da legitimidade e da eficiência dos atos da Administração Pública, da redução do distanciamento entre esta e a sociedade, da instrumentalização ampliada do controle e da fiscalização e, ainda, da ruptura da tradição do sigilo administrativo. 
Nesse contexto, surge o seguinte problema de pesquisa: quais os limites e possibilidades do processo de publicidade das ações de gestão pública e transparência de informações no município de São Luís? A presente pesquisa encontra-se dividida em três partes: composta pela definição de transparência e dos principais princípios que regem a Administração Pública, aspectos da gestão de saúde no município de São Luís, e a conformidade daquilo apresentado com o que é exigido pela Lei de Acesso à Informação.

Trata-se de uma pesquisa descritiva e exploratória, com utilização de procedimento bibliográfico e documental. Para alcançar o objetivo pretendido, foi realizada coleta de dados na legislação vigente e também em documentos, artigos e doutrina, relacionados ao tema nas seguintes revistas científicas: Revista de Administração Pública da Fundação Getúlio Vargas, Revista de Estudos CEPE, Revista Informação \& Informação. Revista Sociedade e Estado, Revista de Administração da FATEA e nos seguintes bancos de dados: SciELO, Portal de periódicos CAPES, UFMA, entre outros. Aplicou-se metodologia qualitativa, visto que se pretendeu realizar análise das modificações na gestão em saúde após a regulamentação da lei de acesso à informação.

\section{A TRANSPARÊECIA DOS GASTOS PÚBLICOS}

A concepção de transparência na gestão pública tem sido abordada em países que defendem o processo democrático de acesso às informações sobre a ação dos gestores públicos. Bellver e Kaufmann (2005) asseguram que nas sociedades democráticas, o acesso à informação e a transparência também podem ser considerados como direitos humanos fundamentais. Em linhas gerais, Cruz et al. (2010) afirmam que uma gestão transparente tem como principais características o acesso às informações compreensíveis para todo o cidadão e a abertura para a sua participação no governo (controle social).

A transparência é um dos princípios da governança pública ${ }^{3}$ e deve caracterizar todas as atividades realizadas pelos gestores públicos, de maneira que os cidadãos tenham acesso e compreendam aquilo que os gestores governamentais têm realizado a partir do poder de representação que lhes foi confiado. Dessa forma, salientam Cruz et al. (2010) que a

\footnotetext{
${ }^{3}$ Governança pública pode ser compreendida, de acordo com Bizerra (2012, p. 4) como o conjunto de princípios básicos e práticas que conduzem a administração pública ao alcance da eficiência, eficácia e efetividade nos seus resultados, através de um melhor gerenciamento dos seus processos e de suas atividades, promovendo a prestação de contas responsável por parte dos gestores e a transparência de suas ações.
} 
divulgação de informações acerca dos atos da gestão pública não deve se limitar aos relatórios já previstos em dispositivos legais (em geral relatórios fiscais e financeiros), mas também deve ser feita a partir de informações qualitativas que reportem desempenho, projetos e atingimento de metas em áreas relevantes para a sociedade, tais como saúde, educação, cultura, transporte, saneamento e outras. Entende-se que não basta que a informação seja disponibilizada, é importante que seja acessível ao cidadão e mais do que isso: compreensível.

Vê-se que dar transparência aos atos realizados pelos representantes do poder público não é fácil, apesar dos modernos recursos tecnológicos existentes, pois, de acordo com Gomes Filho (2005) a transparência na gestão pública exige política e legislação específicas.

A transparência está relacionada à "disposição de informar" ou ainda responsabilidade em prestar contas em decorrência da responsabilidade da gerência de recursos públicos (CRUZ, 2010). Ela não deve se reportar somente a fatos presentes praticados pela administração pública, mas também ser garantida para informações de períodos anteriores, o que possibilita estudos de caráter evolutivo e comparativo acerca da atuação dos gestores. Dessa forma, segundo Cruz et al. (2010), a transparência cumpre a função de aproximar o Estado e a sociedade e ampliar o nível de acesso do cidadão às informações sobre a gestão pública. Para tanto, tem-se a Lei de Responsabilidade Fiscal - Lei Complementar $n^{\circ}$ 101/2000, a qual previu a possibilidade de divulgação dos instrumentos de transparência da gestão fiscal, ao determinar que a esses instrumentos será dada ampla divulgação em meio eletrônico de acesso público, tal como disposto no artigo 48 da referida lei:

Art. 48. São instrumentos de transparência da gestão fiscal, aos quais será dada ampla divulgação, inclusive em meios eletrônicos de acesso público: os planos, orçamentos e leis de diretrizes orçamentárias; as prestações de contas e o respectivo parecer prévio; o Relatório Resumido da Execução Orçamentária e o Relatório de Gestão Fiscal; e as versões simplificadas desses documentos.

Cruz et al (2010) ressalta que "as tecnologias de informação podem facilitar a transparência e a participação, mas não têm capacidade por si mesmas de pôr fim à existência de déficit democrático e de accountability”. É inegável que a internet já constitui um meio de comunicação de amplo acesso (Pinho, 2006), mas ainda há um imenso potencial de expansão. Mesmo assim, a rede mundial de computadores constitui um ambiente favorável para divulgação ampla e transparente de informações acerca da gestão dos recursos públicos (a exemplo de orçamentos), relatórios de prestação de contas, relatórios de avaliação de 
programas e projetos de iniciativa do poder público, entre outros. Porém, uma gestão pública transparente vai além da divulgação dos instrumentos de transparência fiscal, estende-se quando os cidadãos acompanham e participam efetivamente dos atos da administração pública que causam impactos em toda a sociedade.

É dever de todo ente público informar com clareza à população, como gasta o dinheiro e presta contas dos seus atos. Essas informações devem ser disponibilizadas em uma linguagem que possa ser compreendida por todas as pessoas. De acordo com Rodrigues (2011) o conceito de transparência pública é muito mais abrangente que o de publicidade, pois o simples ato de tornar público algum documento governamental não quer dizer que torne transparente a ação do governo através desta publicidade, pois a transparência requer uma linguagem mais acessível, de fácil compreensão para qualquer cidadão, diferentemente da disponibilizada através de documentos públicos com termos técnicos, como o presente em balanços orçamentários e financeiros.

Vê-se que não basta disponibilizar, tornar público os dados contábeis, é necessária ainda a facilitação do acesso aos dados e informações geradas no âmbito público, facilitação esta que inclui transformar o linguajar tecnicista, próprio do setor público, em linguagem compreensível principalmente ao cidadão comum.

No Brasil, o tema transparência pública vem ganhando importância desde 2011, quando entrou em vigor a Lei de Acesso à Informação e as pessoas começaram a compreender o direito (e até o dever) de acompanhar, fiscalizar e fazer cobranças dos administradores sobre a correta aplicação dos recursos públicos que pertencem ao conjunto da população. Instrumentos legais implementados nos últimos anos, como a Lei de Responsabilidade Fiscal (lei complementar $n^{\circ}$ 101/2000), a Lei da Transparência (lei complementar $n^{\circ} 131 / 2009$ ) e, mais recentemente, a Lei de Acesso à Informação (lei ${ }^{\circ}$ 12.527/2011) são importantes ferramentas de promoção da cidadania visto que possibilitam à população ter conhecimento das ações realizadas pelo poder público.

O alcance da necessidade de transparência dos gastos públicos aumentou gradualmente. Em 2004, o Governo Federal criou o Portal da Transparência e nos anos posteriores, vários Estados e vários Municípios também procederam com a criação de Portais da Transparência. Os portais da transparência têm a importante função de colocar à disposição do público dados referentes às receitas previstas e as despesas fixadas, por exemplo, despesas 
com funcionários, investimento em obras e serviços públicos em saúde, educação, transporte entre outros.

É importante salientar também que já estão em vigor dispositivos legais, como a Lei Complementar $n^{\circ} 101 / 2000$, a Lei Complementar $n^{\circ} 131 / 2009$ e a Lei $n^{\circ}$ 9.755/1998 que obrigam as entidades públicas a divulgar relatórios periódicos com os resultados da aplicação dos recursos públicos previstos nos instrumentos orçamentários, cujo objetivo é promover o acompanhamento por parte da sociedade da aplicação dos recursos públicos e responsabilizar os gestores que descumprirem as normas.

Nesse sentido, vê-se que para promover o acompanhamento da aplicação dos recursos públicos a ser feito por parte da sociedade são apresentados mecanismos jurídicos e práticos. O termo "mecanismos jurídicos e práticos para o controle do dinheiro público" refere-se à possibilidade de análise dos aspectos constitucionais e infraconstitucionais referentes ao tema e também à exemplificação de ocorrências de ordem prática, como a existência de endereços eletrônicos nos quais se fazem presentes informações sobre as contas estatais de modo acessível ao público. Deste modo, aborda-se alguns desses instrumentos. Os primeiros instrumentos a serem analisados são os jurídicos, iniciando pela abordagem principiológica.

O princípio da publicidade é um dos importantes princípios constitucionais que regem a Administração Pública como um todo. A publicidade para Meirelles (1992) abrange a divulgação de atos tanto concluídos, quanto em formação, assim como de processos em andamento, pareceres de órgãos técnicos e jurídicos, atas de julgamentos de licitações e de contratos, prestações de contas, ou seja, qualquer documento público que o cidadão possua o interesse de examinar. Esse princípio é importante para garantir a transparência da administração pública e impedir possíveis $\operatorname{desvios}^{4}$, mas caso estes ocorram, ou mesmo não seja respeitado o princípio da publicidade, é garantido constitucionalmente ao cidadão o direito à informação.

\footnotetext{
${ }^{4}$ A determinação legal do princípio da publicidade e do dever de transparência da gestão pública pode ser visualizada na Lei Complementar no 101/2000 (Lei de Responsabilidade de Fiscal), a qual, em seu artigo 48, por exemplo, preleciona que: São instrumentos de transparência da gestão fiscal, aos quais será dada ampla divulgação, inclusive em meios eletrônicos de acesso público: os planos, orçamentos e leis de diretrizes orçamentárias; as prestações de contas e o respectivo parecer prévio; o Relatório Resumido da Execução Orçamentária e o Relatório de Gestão Fiscal; e as versões simplificadas desses documentos.
} 
O direito à informação é o direito de requerer informações necessárias para fomentar o controle e possibilitar a melhor gestão da coisa pública. O artigo $5^{\circ}$, inciso XXXIII da Constituição Federal de 1988 mostra que:

Todos têm direito a receber dos órgãos públicos informações de seu interesse particular, ou de interesse coletivo ou geral, que serão prestadas no prazo da lei, sob pena de responsabilidade, ressalvadas aquelas cujo sigilo seja imprescindível à segurança da sociedade e do Estado.

A Constituição também previu o direito de petição, que consiste no direito inerente ao cidadão de participar das decisões políticas do país que venham a refletir na vida de cada cidadão. Para Moraes (2009): “o direito de petição é uma prerrogativa democrática de caráter informal e se apresenta como instrumento de participação político-fiscalizatório dos negócios do Estado que tem por finalidade a defesa da legalidade constitucional e do interesse público geral. Reis (2006) considera que o direito de petição serve também para fundamentar requerimento de informações acerca da gestão administrativa dos governantes, a fim de propiciar o controle do Estado pelos cidadãos.

Em resumo, Salgado et al (2013) consideram que o instituto constitucional em estudo é um direito subjetivo público de dirigir petições como forma de defesa de direitos ou contra atos ilegais ou abusivos de poder, de índole democrática e cidadã, expressão dos fundamentos e princípios estruturantes da Carta Constitucional brasileira e informadores de todo o ordenamento jurídico pátrio.

Por último, a Constituição Federal de 1988 também previu o direito de todo e qualquer cidadão propor ação popular. De acordo com o art. $5^{\circ}$, inciso LXXIII, da Constituição Federal:

LXXIII - qualquer cidadão é parte legítima para propor ação popular que vise a anular ato lesivo ao patrimônio público ou de entidade de que o Estado participe, à moralidade administrativa, ao meio ambiente e ao patrimônio histórico e cultural, ficando o autor, salvo comprovada má-fé, isento de custas judiciais e do ônus da sucumbência;

Esse instituto representa a manifestação direta da soberania popular e instrumento através do qual o cidadão pode realizar atividade fiscalizatória e de controle do patrimônio do povo. Um terceiro mecanismo jurídico visualizado como importante para a obtenção de 
controle dos recursos públicos é a garantia do direito de participação na administração pública. A Constituição Federal estabeleceu as bases para a participação dos cidadãos, no artigo $37, \S 3^{\circ}$ :

\footnotetext{
$\S 3^{\circ} \mathrm{A}$ lei disciplinará as formas de participação do usuário na administração pública direta e indireta, regulando especialmente:

I - as reclamações relativas à prestação dos serviços públicos em geral, asseguradas a manutenção de serviços de atendimento ao usuário e a avaliação periódica, externa e interna, da qualidade dos serviços;

II - o acesso dos usuários a registros administrativos e a informações sobre atos de governo, observado o disposto no art. $5^{\circ}$, X e XXXIII.

III - a disciplina da representação contra o exercício negligente ou abusivo de cargo, emprego ou função na administração pública.
}

Desse modo, conforme preleciona Reis (2006), o cidadão, aqui tratado como usuário do serviço público, está credenciado a interagir com a administração pública, apresentando reclamações quanto à prestação do serviço, representando contra a atuação negligente ou abusiva de servidor público.

A Lei n. 8.142/1990 dispõe sobre a participação da comunidade, representantes de segmentos sociais, profissionais de saúde, usuários, Conselhos de Saúde, na gestão do Sistema Único de Saúde (SUS), desde a formulação de políticas públicas até o controle da execução destas.

COSTA (2013) relata que em várias cidades ficou a cargo das prefeituras não apenas criar os conselhos, mas também estimular a participação dos grupos sociais. Ocorre que em muitos municípios os prefeitos acabavam indicando, como ainda hoje indicam, parentes, amigos ou funcionários da prefeitura para compor os respectivos conselhos e as conferências de saúde (CORTES, 2004). Tendo por base a lei supracitada (Lei $\mathrm{n}^{\circ}$ 8.142/90), para abarcar a participação do povo na administração pública de saúde, CAMPOS (2013, p 255) considera que:

(...) o poder legislativo deve dispor de uma Comissão de Saúde e atuar em articulação permanente com os conselhos de saúde, propondo que suas atribuições considerem as análises e recomendações dos respectivos conselhos. Nessa perspectiva, a aprovação do orçamento da saúde pelo Legislativo local deve considerar o Plano de Saúde aprovado pelo Conselho. Esta dinâmica pressupõe que o conselho seja capaz de trazer novas proposições e alternativas para a saúde, traduzindo as aspirações populares e aproximando o planejado das reais necessidades de saúde do território. 
Como a maioria dos conselheiros dos municípios brasileiros são escolhidos por integrantes do Executivo, pode ser visualizada baixa efetividade das atividades desse órgão, devendo existir uma forma de escolha imparcial. Ainda sobre o tema, trata ABRANCHES, AZEVEDO (2004):

\begin{abstract}
Vem sendo observada a perda do caráter da diversidade e do poder da representação nesses espaços. Isso se dá pela formação de uma "elite de referência", ou seja, pelo exercício de um poder maior de um grupo sobre o conjunto de atores que, geralmente, apresentam maior capacitação técnica ou política, maior perfil socioeconômico e que consegue ter maior poder de influência em relação a outras representações.
\end{abstract}

Uma extensão da participação da sociedade civil em assuntos relacionados à administração pública, é a regulamentação constitucional do direito de denunciar, disposta no $\S 2^{\circ}$ do artigo 74 da Constituição Federal de 1988. Consiste no fato de que qualquer cidadão, partido político, associação ou sindicato é parte legítima para, na forma da lei, denunciar irregularidades ou ilegalidades perante o Tribunal de Contas da União.

Ressalta-se que, tanto o Ministério Público, como o Poder Judiciário são aliados do cidadão no exercício do controle popular do dinheiro público. No entanto, se denúncias recaírem sobre os serviços prestados por membros ou serviços administrativos desses órgãos, a Constituição Federal abre a possibilidade de que o cidadão venha endereçá-las aos referidos Conselhos Nacionais para as apurações ali competentes.

Reis (2006) considera que é importante asseverar que o cidadão está legitimado a representar contra irregularidades não só nos Tribunais de Contas, nas Comissões do Congresso e nos Conselhos Nacional de Justiça e do Ministério Público, mas em todo e qualquer órgão público com legitimidade para dar encaminhamento à denúncia, como é o caso do Ministério Público, por excelência fiscal da lei, da Controladoria Geral da União (CGU), Agências Reguladoras e de outros.

Outra importante forma de participação das decisões da administração pública é através do acompanhamento do desenvolvimento de licitação. Sobre o tema, trata o artigo $4^{\circ}$ da Lei de Licitações e Contratos (lei no 8.666/1993):

Artigo $4^{\mathrm{o}}$ : Todos quantos participem de licitação promovida pelos órgãos ou entidades a que se refere o art. $1^{\circ}$ têm direito público subjetivo à fiel observância do pertinente procedimento estabelecido nesta lei, podendo qualquer cidadão 
acompanhar o seu desenvolvimento, desde que não interfira de modo a perturbar ou impedir a realização dos trabalhos.

A prática do acompanhamento do processo de licitação pelos cidadãos tem o condão de inibir irregularidades, como por exemplo, a simulação da realização dos certames. A lei de licitação estabelece em seu artigo 15 , parágrafo $6^{\circ}$ que "Qualquer cidadão é parte legítima para impugnar preço constante do quadro geral em razão de incompatibilidade desse com o preço vigente no mercado".

Segundo Reis (2006), trata-se de mais um importante instrumento a favor do controle pela sociedade das gestões públicas, mas que sua utilização pressupõe a transparência dessas informações.

Por outro lado, os instrumentos práticos utilizados para realização do controle do dinheiro público tratam-se, segundo Reis (2006) de mecanismos que, materializando, em parte, o dever de transparência da administração, facilitam o acesso a informações úteis ao exercício do controle popular do dinheiro público. São, por exemplo, endereços eletrônicos da rede mundial de computadores - a Internet - mantidos por entidades públicas que disponibilizam dados diversos relacionados à gestão da coisa pública e que facilitam a tarefa do cidadão de informar-se para bem controlar a coisa pública. Cruz (2012) assevera que:

\footnotetext{
A rede mundial de computadores (Internet) tem realizado significativas mudanças no processo de comunicação humana, de modo que as formas tradicionais de comunicação atualmente contem com o auxílio de recursos tecnológicos que permitem que a distância geográfica se torne um conceito relativo.
}

Citam-se como exemplos de dados relacionados à gestão da coisa pública disponíveis para consulta: o orçamento geral da União, os montantes das transferências constitucionais e legais, os montantes do Sistema Único de Saúde - SUS, os beneficiários do programa bolsa família, compras do governo federal, contas públicas, cadastro de contas irregulares com débito entre outros dados.

Para Cruz (2012), a transparência deve caracterizar todas as atividades realizadas pelos gestores públicos, de maneira que os cidadãos tenham acesso e compreensão daquilo que os gestores governamentais têm realizado a partir do poder de representação que lhes foi confiado. Deve haver o acompanhamento da execução orçamentária e das finanças públicas. Mas, para que isso ocorra, não basta que as informações estejam dispostas em sites, é necessário que elas sejam capazes de efetivamente comunicar. Na opinião de Matias - Pereira 
(2006), para falar em transparência é necessário observar a existência de informação livre, disponível, compreensível, diretamente acessível aos que serão afetados pelas decisões delas decorrentes, prestadas de forma completa em meios de comunicação adequados.

A tecnologia da informação tem o condão de facilitar a divulgação de atos de gestão da Administração Pública, mas ainda não foi dado ao cidadão o amplo acesso, pois há uma discrepância entre aquilo disponibilizado e aquilo que os cidadãos de qualquer área, nível econômico social podem compreender.

\section{A GESTÃO DO SISTEMA DE SAÚDE BRASILEIRO}

A partir do século $\mathrm{XX}$, após as duas grandes guerras, iniciou-se no mundo a preocupação com a garantia da proteção sanitária, colocando-a como uma das pautas das políticas de governo. Foi também no século XX que houve a criação da Organização das Nações Unidas, Declaração Universal dos Direitos Humanos, que ensejaram a criação da Organização Mundial de Saúde. Dessa forma, a partir do pós-guerra, os gastos em saúde vêm crescendo mundialmente, por diversos fatores, que de acordo com Médici (1993) são: a extensão horizontal e vertical da cobertura ${ }^{5}$; envelhecimento da estrutura etária da população ${ }^{6}$; mudanças no campo da tecnologia médica, nas funções de produção em saúde e seus impactos na produtividade ${ }^{7}$ e ainda custos de medicamentos. Além desses fatores, no Brasil, particularmente, ainda se faz necessário lidar com o problema da corrupção, de forma que se torna necessário criar mecanismos capazes de realizar o gerenciamento dos gastos públicos em saúde para que, preceitos constitucionais como a universalização da cobertura e a concepção de que o acesso integral aos serviços de saúde é direito dos cidadãos e dever do Estado possam ser atingidos.

\footnotetext{
${ }^{5}$ Como extensão horizontal tem-se a inclusão de novos segmentos como clientela dos serviços de saúde, que se deu de forma gradativa, a depender do país a ser considerado. Por extensão vertical de cobertura, define-se a complexidade e a diversificação da oferta de serviços médico-sanitários, assistência odontológica, psicanálise, terapias de alto custo como diálise renal, terapias alternativas, etc.

${ }^{6}$ A população envelhece e os recursos médicos que devem ser dispensados a esse segmento se tornam maiores, visto que a complexidade dos serviços prestados, assim como a frequência da necessidade destes tende a aumentar

7 Ao melhorar o diagnóstico e a qualidade dos serviços de saúde, torna-se necessário mais capital para equipamentos como mais recursos humanos (novas profissões que possam operar e interpretar os novos meios tecnológicos). Nesse sentido, há o encarecimento dos serviços de saúde.
} 
Para Ferraz (2015, p. 479): “Os resultados em políticas públicas são decorrentes da gestão e integração das fases de um processo que começa com o planejamento e será concluído pela fase da avaliação". Por outro lado, Santos (2010) acredita que é possível melhorar a gestão dos recursos públicos, mesmo não havendo mudanças estruturais na Administração Pública. Na área da saúde, em especial, seria necessário acabar com algumas ilegalidades e esclarecer algumas normas. Nas palavras de Santos (2010):

\begin{abstract}
O primeiro ponto a ser considerado no tocante às ilegalidades é a questão das partilhas de recursos financeiros da saúde, que até o presente momento não respeita o disposto na lei n. $.^{\circ} 8.080 / 1990$, artigo 35 e na lei n. ${ }^{\circ} 8.142 / 90$, artigos $3^{\circ}$ e $4^{\circ}$. Essas partilhas acabam sendo realizadas por adesão a programas e projetos do Ministério da Saúde, não se cumprindo o mandamento legal de que 50\% dos recursos deveriam ser pelo critério populacional e o restante pelos demais critérios previstos no artigo 35 da lei n. ${ }^{\circ} 8.080 / 1990$.
\end{abstract}

Outro ponto imprescindível para a melhor gestão dos gastos públicos em saúde é a relevância dada à divisão das atribuições do SUS, como: delimitação das competências de órgãos e entes públicos na área da saúde, de acordo com o que já está inscrito na Constituição, artigo $200^{8}$ e na Lei n. ${ }^{\circ}$ 8.080/1990, a respeito do que são ações e serviços de saúde, de modo que os entes federativos não venham a incluir na conta da saúde ações e serviços próprios de outras áreas, como a Previdência Social (pagamento de inativos); alimentação (cestas básicas); saneamento, desconsiderando o disposto no artigo $32, \S 3^{\mathrm{o} 9}$, e assim por diante.

O SUS é um sistema de saúde 'descentralizado' em suas ações e serviços e 'unitário' em seus princípios e diretrizes, em seus conceitos e bases. Porém, na prática, há uma verticalização de programas que influencia o planejamento da saúde e os planos de saúde dos

\footnotetext{
${ }^{8}$ Art. 200. Ao sistema único de saúde compete, além de outras atribuições, nos termos da lei:

I - controlar e fiscalizar procedimentos, produtos e substâncias de interesse para a saúde e participar da produção de medicamentos, equipamentos, imunobiológicos, hemoderivados e outros insumos;

II - executar as ações de vigilância sanitária e epidemiológica, bem como as de saúde do trabalhador;

III - ordenar a formação de recursos humanos na área de saúde;

IV - participar da formulação da política e da execução das ações de saneamento básico;

$\mathrm{V}$ - incrementar em sua área de atuação o desenvolvimento científico e tecnológico;

$\mathrm{V}$ - incrementar, em sua área de atuação, o desenvolvimento científico e tecnológico e a inovação; (Redação dada pela Emenda Constitucional n ${ }^{\circ} 85$, de 2015)

VI - fiscalizar e inspecionar alimentos, compreendido o controle de seu teor nutricional, bem como bebidas e águas para consumo humano.

VII - participar do controle e fiscalização da produção, transporte, guarda e utilização de substâncias e produtos psicoativos, tóxicos e radioativos;

VIII - colaborar na proteção do meio ambiente, nele compreendido o do trabalho.

${ }^{9} \S 3^{\circ}$ As ações de saneamento que venham a ser executadas supletivamente pelo Sistema Único de Saúde (SUS), serão financiadas por recursos tarifários específicos e outros da União, Estados, Distrito Federal, Municípios e, em particular, do Sistema Financeiro da Habitação (SFH).
} 
entes federativos. Por isso, a característica de descentralização não se faz perceptível, dificultando a gestão pública da saúde.

A administração pública vem abrindo espaço para atuações administrativas instrumentalizadas por técnicas contratuais, decorrentes de consenso, acordo, cooperação, parcerias firmadas entre a Administração e particulares ou entre órgãos públicos e entidades estatais (Medauar, 2003). Um exemplo é o contrato de gestão, que surgiu nos anos 1990, pelo decreto n. ${ }^{\circ}$ 137/1991 e tem sido utilizado no âmbito da administração pública nas relações que mantém com as Organizações Sociais, com o Serviço Social Autônomo, com as agências reguladoras, agências executivas e com as empresas estatais. Define-se como um contrato firmado entre o Estado com entes geridos pelo direito privado, repassando para eles recursos do fundo público em troca da prestação de serviços. Segundo Medauar (2003) o contrato de gestão é um instrumento do Programa de Gestão das Empresas Estatais (PGE), no qual se estipulam compromissos reciprocamente assumidos entre a União e a Empresa'.

O contrato de gestão feito com organizações sociais, fundações públicas de direito privado, empresas públicas significa, para Cislaghi (2011) "uma entrega do patrimônio do SUS para o setor privado, numa lógica de empresariamento da saúde". Observa-se que a Administração Pública deve buscar garantir o direito à saúde engajando seus gestores nas discussões que ora se promovem quanto às alterações da legislação de organização administrativa vigentes; quanto à cessação de ilegalidades cometidas por autoridades públicas, como é o caso das transferências constitucionais dos recursos da saúde e quanto ao disciplinamento de brechas legislativas essenciais para a gestão da saúde, como o padrão de integralidade, a qual compreende a assistência farmacêutica.

Nesse sentido, para Schmidt (2007), novos paradigmas para a gestão pública precisam existir. Não se devem descartar aspectos importantes do mundo empresarial que podem inovar a administração pública, desde que princípios públicos sejam a eles associados, como a participação comunitária, a transparência administrativa, a impessoalidade, a fiscalização, amarrando as políticas públicas, a capacidade de planejamento que levem em conta a política e as diferentes dimensões da vida social.

Com decisão política, controle feito pela sociedade, prática efetiva da democracia participativa, obediência à repartição de recursos, com a aplicação dos recursos mínimos para cuidados em saúde haverá condições de ser realizada a gestão do sistema de saúde, garantindo 
a implantação e funcionamento do SUS de forma sintonizada com os princípios referentes ao direito humano fundamental à saúde, previstos constitucionalmente.

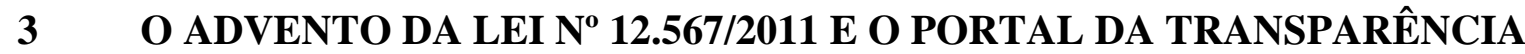

\section{EM SÃO LUÍS: uma breve análise sobre a disponibilidade de informações referente à} saúde

Poder acessar informações orçamentárias é fundamental para a transparência do setor público e, assim, aumentar sua efetividade.

No Brasil, a disponibilização de dados referentes à gestão pública se intensificou a partir da aprovação da Lei de Acesso à Informação (LAI), Lei n ${ }^{\circ} 12.527$ de 18 de novembro de 2011, a qual regula os procedimentos a serem observados pelos entes federados com o fim de garantir o acesso da sociedade à informação e prevê que os órgãos e entidades públicas estão obrigados a disponibilizar informações públicas, que não sejam sigilosas, em portal da internet ou através de requerimento específico de forma fácil e desburocratizada.

Amorim et al (2014) afirmam que "o surgimento do ciberespaço acontece num contexto de aumento da visibilidade e da transparência, em que a "esfera pública" é definida como um espaço compartilhado de visibilidade e comunicação coletiva".

Dessa forma, os dados sobre orçamento público são disponibilizados por meio de ferramentas digitais e, atualmente, é possível encontrar páginas eletrônicas de transparência orçamentária tanto em nível federal como estadual e municipal. Em nível federal, atendendo ao previsto na LAI e regulamentado no Decreto $n^{\circ} 7.724 / 2012^{10}$, os órgãos públicos criaram, progressivamente, formas de dar acesso aos dados como: sítios eletrônicos por unidade orçamentária.

As principais ferramentas de disponibilização de dados orçamentários concentrados da União são o Portal da Transparência do Governo Federal, uma iniciativa da Controladoria Geral da União (CGU), existente desde novembro de 2004, a qual gerou forte impacto na sociedade brasileira por ser a precursora; o Portal Siga Brasil o qual é uma iniciativa do Senado Federal que consiste em um sistema de informações sobre orçamento público que permite bases de dados sobre planos e orçamentos públicos por meio de uma única ferramenta

10 Que regulamenta a lei de Acesso à Informação e engloba a questão da transferência ativa considerando no artigo $7^{\circ}$ do referido decreto que "é dever dos órgãos e entidades promover, independente de requerimento, a divulgação em seus sítios na Internet de informações de interesse coletivo ou geral por eles produzidas ou custodiadas, observado o disposto nos arts. $7^{\circ}$ e $8^{\circ}$ da Lei no 12.527, de 2011. 
de consulta; e o Orçamento Federal ao Alcance de Todos (OFAT), da Secretaria de Orçamento Federal (SOF), um documento simplificado que visa potencializar a acessibilidade aos complexos dados orçamentários.

No Estado do Maranhão, vigora a Lei $\mathrm{n}^{\circ} 10.217$ de 24 de março de 2015, a qual dispõe sobre regras específicas para garantir o acesso a informações no âmbito do estado do Maranhão. Outra novidade foi a criação a partir da Medida Provisória ${ }^{\circ} 186$, de 02 de janeiro de 2015, da Secretaria de Estado de Transparência e Controle, convertida na Lei no 10.204, de 23 de fevereiro de 2015, tornando-se o órgão central do Sistema de Controle Interno, sucedendo a Controladoria Geral do Estado. A referida Secretaria de Estado ainda traz consigo a fundação do Sistema de Controle Social com a integração de outros órgãos setoriais de controle social ${ }^{11}$.

\begin{abstract}
A partir do início do ano de 2015, o Governo do Maranhão passou a priorizar as ações de transparência, criando a Secretaria de Estado de Transparência e Controle, incorporando novas funções ao sistema de controle interno, retirando-se filtros indevidos encontrados no antigo Portal da Transparência, lançando um novo Portal, regulamentando a Lei de Acesso à Informação no âmbito estadual, aderindo ao Programa Brasil Transparente, da Controladoria Geral da União (CGU), nomeando trinta e três novos auditores, dobrando a capacidade do controle interno e criando a Força Estado de Transparência e Controle - Fetracon ${ }^{12}$, priorizando a realização de auditorias materiais, com fiscalização in locu, nas obras públicas financiadas com recursos dos cofres estaduais (Governo do Maranhão, 2015).
\end{abstract}

Esse ainda é o segundo ano de vigência da Lei de Acesso à Informação Estadual, assim como de mudança organizacional com a atuação da Secretaria de Estado de Transparência e Controle. Conforme disposto no site do governo estadual, foram nomeados mais auditores os quais trabalham inicialmente na fiscalização, auditoria - com o auxílio da Força Estado de Transparência e Controle (Fetracon), dos dados contábeis de obras públicas de engenharia civil.

Além do governo do Estado, a prefeitura municipal de São Luís também atualizou o seu portal da transparência. O Portal da Transparência tem o objetivo de divulgar dados e informações dos órgãos da Administração Pública Municipal na internet.

\footnotetext{
${ }^{11}$ Informações obtidas a partir do site do governo do estado do Maranhão.

12 Tem como objetivo auxiliar a Secretaria de Estado da Transparência e Controle quanto à defesa do patrimônio público, ao controle interno, à auditoria pública, à correição, à prevenção e ao combate à corrupção, às atividades de ouvidoria e ao incremento da transparência da gestão no âmbito da Administração Pública Direta ou Indireta.
} 
As páginas apresentam informações sobre os gastos realizados com a folha de pagamento da Administração Direta (Recursos Humanos), com o Planejamento Orçamentário autorizado pela Câmara Municipal e sobre a execução orçamentária do exercício, atualizada, com dados de gastos com fornecedores em suas diversas modalidades ${ }^{13}$.

Em agosto de 2015 houve a publicação do decreto municipal $\mathrm{n}^{\circ} 47.272$ regulamentando a Lei Federal $n^{\circ}$ 12.527, de 18 de novembro de 2011, no âmbito do Poder Executivo, nos mesmos moldes do decreto federal obedecendo às particularidades municipais. De acordo com o decreto municipal $n^{\circ} 47.272 / 2015$, no que se refere à transparência ativa, considera-se:

Art. 10. (...). $\S 1^{\circ}$. Serão divulgadas no Portal da Transparência, na Internet, sem prejuízo da divulgação em outros sítios dos órgãos e entidades municipais, as informações sobre:

I - repasses ou transferências de recursos financeiros; II - execução orçamentária e financeira detalhada; III - licitações realizadas e em andamento, com editais, anexos e resultados; IV - contratos firmados, na íntegra; V - íntegra dos convênios firmados, com os respectivos números de processo; VI - remuneração e subsídios recebidos por ocupantes de cargos, empregos ou funções públicas, incluídos eventuais auxílios, ajudas de custo, jetons e quaisquer outras vantagens pecuniárias, bem como proventos de aposentadoria e pensões, de forma individualizada, conforme ato da Secretaria Municipal de Planejamento, Orçamento e Gestão.

Cabe neste ponto analisar o que de fato está discriminado no Portal da Transparência Municipal, se está de acordo com o que preleciona o artigo $10, \S^{\circ}$ do decreto $n^{\circ} 47.272 / 2015$. As informações estão dispostas para que sejam consultadas por qualquer contribuinte e/ou usuário do serviço público, no entanto as informações estão incompletas e fragmentadas, a linguagem utilizada é extremamente técnica e pouco inteligível, própria para especialistas em contabilidade pública, de forma que, mesmo apresentado um corpo robusto de informações, verifica-se que são pouco acessíveis aos cidadãos.

Ainda há avanços a serem realizados. Em 2014, o Portal da transparência do município de São Luís alcançava a $24^{\mathrm{a}}$ posição no ranking nacional ${ }^{14}$, em 2015 , atingiu a $17^{\mathrm{a}}$, conforme averiguação do Ministério Público Federal. Faz-se necessário aperfeiçoar e inserir ferramentas de buscas rápidas, por área, secretaria, órgão de interesse para que a consulta seja realizada de forma mais ágil, enquadrar o portal no padrão ideal de URL (http://transparencia.saoluis.ma.gov.br), ativar o link da Ouvidoria, incluir nomes de

\footnotetext{
${ }^{13}$ Informações obtidas no site da Prefeitura Municipal de São Luís/MA.

${ }^{14}$ Informação obtida no site "Índice de Transparência: <https://indicedetransparencia.com/sao-luis-2014/.>.
} 
servidores e nomes dos cargos e não apenas fazer uma apresentação por siglas, facilitar mecanismos de busca de despesas-execução por secretarias, que não estão dispostas ao clicar em um único link.

No que se refere às informações referentes à Secretaria Municipal de Saúde, estas não constam no link indicativo do Portal da Transparência em que se encontram as demais secretarias, mas em link diverso, topografia que dificulta a visualização imediata para o cidadão comum. Além disso, as informações estão inacabadas, tendo em vista que há apenas a discriminação de despesas por mês ou de forma acumulada (anual), o macula o preceituado no inciso $\mathrm{II}^{15}$ do artigo $10 \S 1^{\circ}$ do Decreto Municipal $\mathrm{n}^{\mathrm{o}} 47.272 / 2015$ que regulamenta a Lei Federal $n^{\circ} 12.527 / 2011$

Não há a correta indicação da destinação do dinheiro público para a saúde no link de despesas ou mesmo receitas vinculadas à saúde, no campo de receitas. Apenas ao abrir o relatório de gestão fiscal é que é possível obter algumas dessas informações, mas ainda assim é um relatório com índices anuais e mensais, que não traz informações com exatidão. Ao acessar o demonstrativo do cronograma de execução mensal, por cinco vezes, em dias diferentes da semana durante todo o mês de agosto do corrente ano, no período vespertino, a página não estava disponível. Ao tentar uma sexta vez, na primeira semana de setembro, foi possível ter acesso apenas aos dados do ano de 2016, embora o portal disponibilize link de acesso aos seis últimos anos.

Faz-se importante o aperfeiçoamento do portal da transparência, pois apenas com informações claras, precisas, fáceis de adquirir que poderá ser dito que efetivamente tem sido garantido o direito à informação acerca dos gastos públicos.

Quando os cidadãos buscam as referidas informações, que estejam dispostas a um clique, a qualidade da democracia melhora e diminuem as brechas para a ocorrência de fraudes e corrupção. Sobre a corrupção, Lopes (2007) trata:

A corrupção traz grandes perdas para a sociedade, como arrecadação tributária, inflação, impacto na riqueza, redução do crescimento econômico e de incentivos aos investimentos privados. Também reduz a renda per capita, aumenta a mortalidade

15 Entende-se por execução orçamentária e financeira detalhada a apresentação de receitas detalhadas por categoria econômica, origem e espécie, especificando a previsão inicial, a previsão atualizada para o exercício, a receita realizada e o saldo a realizar, conforme a Secretaria do Tesouro Nacional, tendo por base a lei $n^{\circ}$ $4.320 / 1964$ 
infantil, além de impactar negativamente os indicadores de saúde, de educação, de produtividade.

Alcançar um patamar de viver em um município sem corrupção, em especial no âmbito da saúde, ainda soa como utópico, mas a partir de dispositivos legais, como a lei de acesso à informação, visualizou-se a possibilidade de ocorrência de redução da corrupção, por meio de um processo continuado e permanente de melhorias institucional, cultural e da mudança de postura da própria sociedade.

\section{CONSIDERAÇÕES FINAIS}

O cidadão é figura principal quando o assunto é dotação orçamentária. Quanto maior o poder de fiscalização e o interesse do cidadão em fazer parte e ser participativo no processo de verificação da utilização de recursos públicos para prestação de serviços públicos pelos agentes do Executivo, maior a possibilidade de prestação desses serviços de modo satisfatório.

Novos paradigmas para a gestão pública são necessários. Não se devem descartar princípios sejam à administração pública associados, como a participação comunitária, a transparência administrativa, a impessoalidade, a fiscalização, sejam referentes às políticas públicas, à capacidade de planejamento, que levem em conta a política e as diferentes dimensões da vida social.

Entende-se que com decisão política, controle social, prática efetiva da democracia participativa e obediência à legislação vigente é possível ter efetivas condições de implantação definitiva do SUS de forma totalmente sintonizada com os princípios presentes na Constituição Federal, frutos da Reforma Sanitária no Brasil.

Logo, a pesquisa realizada sobre a transparência dos gastos públicos, com destaque para os relacionados à saúde, após a vigência da Lei de Acesso à Informação, buscou revelar avanços do processo de disponibilização dos dados nos portais da transparência, como as deficiências e limitações ainda por serem superadas.

Entre essas limitações está a de tornar o governo realmente transparente, sendo para tanto, na opinião de Loureiro (2008) necessário não só o compromisso com a transparência, mas também a reestruturação dos processos operacionais e administrativos de forma a 
permitir o estabelecimento de um fluxo de informações que possibilite sua disponibilização pública, muitas vezes em tempo real.

São Luís (MA), nos dois últimos anos tem evoluído no que se refere a realizar a transparência ativa e passiva dos dados públicos. Ainda há aperfeiçoamentos a serem feitos, como: inserir link para busca rápida e promover explicação dos termos técnicos em linguagem acessível a todos, oferecer número de telefone ou e-mail para o cidadão entrar em contato no caso de dúvidas, mas a legislação existe, cabendo ao cidadão buscar seu direito à informação, seja nos portais, seja diretamente nas Secretarias Municipais.

Quando o cidadão passa a ter acesso ao que é feito com o dinheiro público e busca esse direito, a tendência é ocorrer a diminuição da corrupção e emprego desses recursos em prol da sociedade, ocorrendo melhorias nos diversos setores sociais, tais como a saúde, tendo como consequência o oferecimento de serviços de qualidade custeados pelo Estado.

\section{REFERÊNCIAS}

ABRANCHES, M. \& AZEVEDO, S. de. A capacidade dos conselhos setoriais em influenciar políticas públicas: realidade ou mito? In: SANTOS JUNIOR, O. A. dos, RIBEIRO, L. C. de Q. \& AZEVEDO, S. de (org.). Governança democrática e poder local. Rio de Janeiro: Revan, Fase, 2004.

AMORIM, Michelle Ribeiro Lage de; et al. Impactos da implantação da lei de acesso à informação no serviço público: uma análise das dificuldades e benefícios à cidadania. XI Simpósio de excelência em gestão e tecnologia, 2014. Disponível em:

<http://www.aedb.br/seget/arquivos/artigos14/8820506.pdf.>. Acesso em: 20 ago. 2016.

BIZERRA, André Luiz Villagelim, et al. Governança pública: uma proposta de conteúdo mínimo para os relatórios de gestão das entidades governamentais. Encontro de

Administração Pública e Governo. Salvador, 2012. Disponível em: <http://www.anpad.org.br/diversos/trabalhos/EnAPG/enapg_2012/2012_EnAPG495.pdf.>. Acesso em: 02 set. 2016.

CAMPOS, Rosana, et al. Gestão da informação pública: um estudo sobre o Portal Transparência Goiás. Revista Sociedade e Estado. Vol. 28, n. 02, mai./ago. 2013. Disponível em: http://www.scielo.br/scielo.php?script=sci_arttext\&pid=S0102-69922013000200012. Acesso em 05 dez. 2015.

CISLAGHI, Juliana Fiúza, et al. O financiamento do SUS: principais dilemas. Anais do I circuito de debates acadêmicos, IPEA, 2011. Disponível em: 
<http://www.ipea.gov.br/code2011/chamada2011/pdf/area2/area2-artigo16.pdf. >. Acesso em: 18 set. 2016.

COSTA, A. M., VIEIRA, N. A. Participação e controle social em saúde. In FUNDAÇÃO OSWALDO CRUZ. A saúde no Brasil em 2030 - prospecção estratégica do sistema de saúde brasileiro: organização e gestão do sistema de saúde [online]. Rio de Janeiro: Fiocruz/Ipea/Ministério da Saúde/Secretaria de Assuntos Estratégicos da Presidência da República, 2013. Vol. 3. pp. 237-271. Disponível em:

<http://static.scielo.org/scielobooks/z9374/pdf/noronha-9788581100180.pdf>. Acesso em 20 ago. 2016.

CRUZ, C.F. Transparência da gestão pública municipal: um estudo a partir dos portais eletrônicos dos maiores municípios brasileiros. Rev. Adm. Pública. vol. 46 n.1, Rio de Janeiro Jan./Fev. 2012. Disponível em: <

http://bibliotecadigital.fgv.br/ojs/index.php/rap/article/view/7080>. Acesso em: 10 ago. 2016.

GOMES FILHO, A.B. O desafio de implementar uma gestão pública transparente. In:

Congreso Internacional del Clad sobre la Reforma del Estado y de la Administración Pública, X, Santiago, 2005. Anais, 2005. Disponível em:

<https://bvc.cgu.gov.br/bitstream/123456789/2698/1/o_desafio_de_implementar.pdf>.

Acesso em: 25 ago. 2016.

G1 MARANHÃO. Maranhão é $10^{\circ}$ e, São Luís, $17^{a}$, em ranking de transparência do MPF: Estado obteve 7,70 e, capital, 7,0, em escala de 0 a 10. Ranking nacional foi divulgado nesta quarta-feira (9) pelo órgão. Jornal G1 Maranhão. Disponível em:

http://g1.globo.com/ma/maranhao/noticia/2015/12/maranhao-e-10-e-sao-luis-17-em-rankingde-transparencia-do-mpf.html> Acesso em: 20 de dez. 2015.

LOUREIRO, Maria Rita; et.al. Construção de instituições democráticas no Brasil contemporâneo: transparência das contas públicas. Revista O \& S. V.15, n. 47, out./dez. 2008. Disponível em: <http://www.scielo.br/pdf/osoc/v15n47/06.pdf>. Acesso em: 18 de dez. 2015 .

LOPES, Cristiano Aguiar. Acesso a informação pública para a melhoria da qualidade dos gastos públicos: literatura, evidências empíricas e o caso brasileiro. Cadernos Finanças Públicas, Brasília, n. 8, p. 5-40, dez. 2007. Disponível em:

$<$ http://www.esaf.fazenda.gov.br/esafsite/publicacoes-esaf/cadernofinancas/ CFP8/CFP_n8_art1.pdf>. Acesso em: 25 jul. 2016.

MARANHÃO. Governo prioriza ações de transparência e acesso à informação . Disponível em: 〈http://www.ma.gov.br/governo-prioriza-acoes-de-acesso-a-informacao/> . Acesso em: 10 de ago. 2016. 
MARANHÃO. Histórico da Secretaria de Transparência e Controle. Disponível em: <http://www.stc.ma.gov.br/historico/>. Acesso em: 25 de jul. 2016.

MARANHAO. Lei No 10217 DE 23/03/2015. Dispõe sobre regras específicas para garantir o acesso a informações no âmbito do Estado do Maranhão, altera a Lei $n^{\circ}$ 6.107, de 27 de julho de 1994, e dá outras providências. Disponível em:

<http://www.legisweb.com.br/legislacao/?id=282452>. Acesso em: 20 de ago. 2016.

MATIAS-PEREIRA, J. Finanças públicas. São Paulo: Atlas, 2006.

MARTINS, Pablo Luiz; VÉSPOLI, Bianca de Souza. O Portal da Transparência como ferramenta para a cidadania e o desenvolvimento. Revista de Administração da Fatea, v. 6, n. 6, p. 93-102, jan./jul., 2013. Disponível em:

<http://publicacoes.fatea.br/index.php/raf/article/viewFile/627/443>. Acesso em: 27 de nov. 2015.

MEDAUAR, O. O direito administrativo em evolução. 2. ed. São Paulo: RT, 2003.

MEDEIROS, Simone Assis, et al. Lei de acesso à informação: em busca da transparência e do combate à corrupção. Revista Informação e Informação, v. 19, n. 1, p. 55 - 75, jan./abr. 2014. Disponível em: <http:www.uel.br/revistas/informacao/>. Acesso em: 08 set. 2016.

MEDICI, André Cezar. Aspectos teóricos e conceituais do financiamento das políticas da saúde. Disponível em:

<http://repositorio.ipea.gov.br/bitstream/11058/3036/4/CAP_2_Economia\%20da\%20sa\%C3 $\%$ BAde $\% 20$ conceitos $\% 20 \mathrm{e} \% 20$ contribui\%C3\%A7\%C3\%A3o\%20para\%20a\%20gest $\%$ C3\% A3o\%20da\%20sa\%C3\%BAde>. Acesso em: 10 de dez. de 2015.

MEDEIROS, Clayton Gomes de. Lei de Acesso à Informação e o Princípio à Transparência na Administração Pública. Disponível em: <http://www.publicadireito.com.br/artigos/?cod=4740fcb3becc721b >. Acesso em: 08 set. 2016.

MINISTÉRIO DA FAZENDA - Secretaria do Tesouro Nacional. Manual de Contabilidade Aplicada ao Setor Público: Parte V - Demonstrações Contábeis Aplicadas ao Setor Público. 3. ed. Brasília, 2010. Disponível em: < http://www3.tesouro.gov.br/legislacao/download/contabilidade/ParteV_DCASP.pdf>. Acesso em: 20 set. 2016. 
MORAES, Alexandre. Direito Constitucional. 24a ed. São Paulo: Editora Atlas, 2009.

PINHO, J. A. G.. Accountability em portais estaduais e municipais no Brasil: realidades distantes das promessas. In: II Encontro de Administração Pública e Governança, São Paulo, 2006. Anais..., São Paulo, ANPAD, 2006.

PIRES, Atrícia Menezes; et.al. Transparência da gestão pública municipal: um estudo dos municípios de Santa Maria e Novo Hamburgo/MS. Revista Estudos do CEPE, Santa Cruz do Sul, n. 38, p.131-160, jul./dez. 2013. Disponível em: <

http://online.unisc.br/seer/index.php/cepe/article/view/3439/3124 >. Acesso em: $01 \mathrm{de} \mathrm{dez.}$ 2015.

PREFEITURA DE SÃO LUÍS. Decreto municipal no 47.272/2015. Regulamenta a lei de acesso à informação. Disponível em:

$<$ http://lei131.com.br/apex/portal/f?p=450:2:0::NO:RP,2:P2_VISAO:141>. Acesso em: 20 de ago. 2016.

REIS, Danilo Adelwal Mendes. O controle popular do dinheiro público, 2006. Monografia. [Bacharelado em Direito]. Faculdade São Luís, São Luís, 2006.

SANTOS, Lenis. Administração Pública e a Gestão da Saúde. In: AMARANTE, Paulo Duarte de Carvalho; SANTOS, Nelson Rodrigues dos. Gestão Pública e Relação Pública e Privada na Saúde. Rio de Janeiro: Cebes, 2010 (Org).

SCHMIDT, J.P. Gestão de políticas públicas: elementos de um modelo pós-burocrático e pós-gerencialista. Direitos sociais e políticas públicas. Santa Cruz do Sul: Edunisp, 2007. 